\title{
BCCN4
}

\section{DEVELOPMENT OF PARTIALLY BIODEGRADABLE FOAMS FROM PP/HMSPP BLENDS WITH NATURAL AND SYNTHETIC POLYMERS}

\author{
Cardoso, E. C. L. ${ }^{(1)}$, Scagliusi, S. R. ${ }^{1}$, Parra, D.F. ${ }^{1}$ and Lugão, A. B. ${ }^{1}$
}

(1) Center for Chemical and Environmental Technology (CQMA), Nuclear and Energy Research Institute, S. Paulo, Brazil

https://doi.org/10.21452/bccm4.2018.13.05

\begin{abstract}
Polymers are used in various applications and in different industrial areas providing enormous quantities of wastes in environment. Among diverse components of residues in landfills are polymeric materials, including Polypropylene, which contribute with 20 to $30 \%$ of total volume of solid residues. As polymeric materials are immune to microbial degradation, they remain in soil and in landfills as a semi-permanent residue. Environmental concerning in litter reduction is being directed to renewable polymers development for manufacturing of polymeric foams. Foamed polymers are considered future materials, with a wide range of applications; high density structural foams are specially used in civil construction, in replacement of metals, woods and concrete with a final purpose of reducing materials costs. At present development, it was possible the incorporation of PP/HMSPP polymeric matrix blends with sugarcane bagasse and PHB in structural foams production. Gamma radiation degradation, at 50, 100, 150, 200 and $500 \mathrm{kGy}$ showed effective for biodegradability induction. Irradiated bagasse blends suffered surface erosion, in favor of water uptake and consequently, a higher biodegradation in bulk structure.
\end{abstract}

Keywords: PP/HMSPP; PHB; sugarcane bagasse; gamma-radiation; biodegradability

\section{INTRODUCTION}

Foamed polymers are future materials, with a comprehensive application field; they are especially used to improve structures appearance or to reduce costs of involved material, besides their applications in construction market. In summary, structural foams (high density foams with density higher than $320 \mathrm{~kg} / \mathrm{m}^{3}$ ), have major applications in automotive industry, in heavy equipment and in civil construction, where they can replace wood, metals and even concrete. Most of thermoplastics can be extruded in order to obtain structural foams and commercial activities are concentrated in thermoplastic of lower cost, as Polypropylene (PP) [1]. PP suffers simultaneously chain-scission and crosslinking, when subjected to ionizing radiation; both chemical phenomena are able to induce changes capable to enhance its use in various applications and in different 
processes. PP is a linear hydrocarbon polymer, originated from a cheap petrochemical material and shows an easy processing for obtaining various products. Consequently, the enormous production and further use lead to an accumulation in environment, because they are not easily degraded by microorganisms and present a serious pollution risk to flora and fauna. In general, polymers fossil based are very bio-resistant, once they have just carbon atoms in backbone chain with non-hydrolysable functional group. Non-degradable plastics accumulate in environment at a rate of 25 million per year. A few possibilities have been considered in order to minimize environmental impact caused by the use of conventional polymers [2,3,4].

When transforming structural foams in biodegradable ones two concepts are fundamental to know: Biodegradation: physical or chemical change, caused by microorganisms action, under heat, moisture, light, oxygen, organic nutrients and Biodegradable Polymers: polymers where degradation results from the action of microorganisms of natural occurrence, as: bacteria, fungus and algae, able to be consumed in weeks or months, under biodegradation favorable conditions $[2,3,4]$. Biodegradable materials can be originated from natural resources or raw-materials, such as: starch, corn, sugarcane bagasse or even oil [5]; biodegradable polymers are provided with some properties as non-toxic and capable to keep an effective mechanical integrity up to their degradation. This paper aims to the assessment of biodegradability characteristics shown by foams from PP/HMSPP with synthetic and natural polymers blends. PP is a semi-crystalline thermoplastic, isotactic, with low melt strength; in order to impart a higher melt strength to PP, it was subjected to gamma-radiation, $12.5 \mathrm{kGy}$ dose, acetylene environment. $50 \% \mathrm{PP} / \mathrm{HMSPP}$ mixture is the ideal base for preparing structural foams [6]. Synthetic polymer involved in this study comprised Poli(hydroxybutirate) - PHB and sugarcane bagasse, as raw-material of agricultural origin.

The present work aimed to investigate the influence of gamma radiation on biodegradability of PHB and sugarcane bagasse PP/HMSPP based foams, in terms of thermal behavior by TG/DTG, mass loss via soil burial test and mechanicals assessments.

\section{EXPERIMENTAL PROCEDURE}

\section{Materials}

Polypropylene (PP): H-503 from Braskem, 3.5 g.(10 min $)^{-1}$ melt index.

High Melt Strength Polypropylene (HMSPP): PP subjected to gamma irradiation, at $12.5 \mathrm{kGy}$, under acetylene environment.

PP/HMSPP, $50 \%$.

PHB: Poli(hydroxibutirate), aliphatic polyester, from renewable source: PHB Industrial S/A, Biocycle ${ }^{\circledR}$, dried at $60{ }^{\circ} \mathrm{C}$ for $12 \mathrm{~h}$ before processing.

Sugarcane bagasse: Caçapava, in S.Paulo state; previously washed in tap water, outdoor dried but protected from bad weather, for 2 months. Dried in air-circulating oven, at $60^{\circ} \mathrm{C}$, for $24 \mathrm{~h}$; further crushed in a blender and kept at $60{ }^{\circ} \mathrm{C}$ in oven, for more $4 \mathrm{~h}$, before segregation in $150 \mu \mathrm{m}$ molecular sieves.

Carbon dioxide): eco-friendly gas, used as physical blowing agent (PBA), to produce a cellular structure by foaming process $[7,8]$.

\section{Blends preparation}

Blends were prepared according to Table 1. PP/HMSPP was used as base for PHB and sugarcane bagasse, by varying both contents from 10, 15, 30 and 50\%. 
Blends were first processed by melting extrusion process, using a twin-screw extruder Haake Rheomex L/D-25.Temperature profile from feed zone to die was 175 to $200{ }^{\circ} \mathrm{C}, 100 \mathrm{rpm}$ screw speed. After exiting die, the extrudates were air-cooled before being granulated in a Primotecnica pelletizer.

Table 1: Designation and composition of blends

\begin{tabular}{cccc} 
Materials & $\begin{array}{c}\text { PP/HMSPP } \\
\text { (wt \%) }\end{array}$ & $\begin{array}{c}\text { PHB } \\
\text { (wt \%) }\end{array}$ & $\begin{array}{c}\text { SCB }^{*} \\
\text { (vol \%) }\end{array}$ \\
\hline PP/HMSPP & 100.0 & --- & --- \\
PP/HMSPP - PHB & 90.0 & 10.0 & --- \\
PP/HMSPP - PHB & 85.0 & 15.0 & --- \\
PP/HMSPP - PHB & 70.0 & 30.0 & --- \\
PP/HMSPP - PHB & 50.0 & 50.0 & --- \\
PP/HMSPP - SCB & 90.0 & -- & 10.0 \\
PP/HMSPP - SCB & 85.0 & --- & 15.0 \\
PP/HMSPP - SCB & 70.0 & --- & 30.0 \\
PP/HMSPP - SCB & 50.0 & --- & 50.0 \\
\end{tabular}

*SCB: Sugarcane Bagasse

Foaming

Processed samples presented in Table 1 were foamed by using $\mathrm{CO}_{2}$ as Physical Blowing Agent (PBA),within 175 to $200{ }^{\circ} \mathrm{C}$ profile temperature, $4 \mathrm{~mm}$ circular die, $30 \mathrm{rpm}$ and 30 bar pressure. Samples were collected directly from die to be further investigated.

\section{CHARACTERIZATION}

Thermogravimetry (TG/DTG): It was used Thermogravimetric Analyzer TGA/SDTA 851 Mettler-Toledo, with thermo-balance, for evaluating sample mass variation in function of temperature, according to ASTM E1641 [9] method. Tests were programmed according to: nitrogen environment, $50 \mathrm{~mL} \cdot \mathrm{min}^{-1}$ flow rate, within 25 to $600{ }^{\circ} \mathrm{C}, 10{ }^{\circ} \mathrm{C} \cdot \mathrm{min}^{-1}$ heating rate. Samples were inserted in aluminum pan, $40 \mu \mathrm{L}$ capacity, $99.999 \%$ purity degree nitrogen and oxygen level lower than 1 ppm (White Martins). Thermogravimetric analyzer was used to obtain thermal degradation and mass loss (residue).

Tensile force and elongation at break: Mechanical essays were accomplished in a TA-HDi (Stable Micro Systems Texture Analyzer) texturometer, $5 \mathrm{~kg}$ (50 N) load cell, operating with a 10 $\mathrm{mm} / \mathrm{sec}$ deformation rate, at room temperature. The specimen dimension was $80 \mathrm{x} 10 \mathrm{~mm}^{2}$ denoting respectively the length and breadth for tensile evaluations.

Soil burial test: Soil burial test methods in plastics were established and standardized for assessing plastics resistance to microorganisms, in function of mass change $[10,11,12]$. The material is buried under controlled conditions of temperature $\left(24^{\circ} \mathrm{C}\right)$ and relative humidity $(80 \%)$; typical analysis accomplished after soil burying is the evaluation of mass loss. Foamed samples aliquots were buried in 1,000 ml capacity beckers containing gardening specific inoculum with water content approximately $20 \%$, wt \%. Recipients were kept in specific conditions of temperature and humidity $\left(24^{\circ} \mathrm{C} \pm 1^{\circ} \mathrm{C} / 80 \%\right.$ relative humidity). Evaluations were accomplished 
after 12 month soil burying, with samples carefully cleaned with brush and towel, before weighing in analytical digital balance BP210D Sartorius AG, RFA model. Mass variation rate was assessed in function of time, according to equation (1):

$$
T(\%)=\frac{m_{\circ}-m_{t}}{m_{\circ}} \times 100
$$

Where $\mathrm{m}_{\mathrm{o}}$ is sample initial mass, at $\mathrm{t}_{\mathrm{o}}$ time, and $\mathrm{m}_{\mathrm{t}}$ is sample mass at $\mathrm{t}$ time, after soil burying.

\section{RESULTS AND DISCUSSION}

\section{Thermogravimetry (TG/DTG):}

\section{Sugarcane bagasse foams:}

TG and DTG curves for bagasse foams presented in Table 1 are shown in Figures 1(a) and 1(b), respectively:

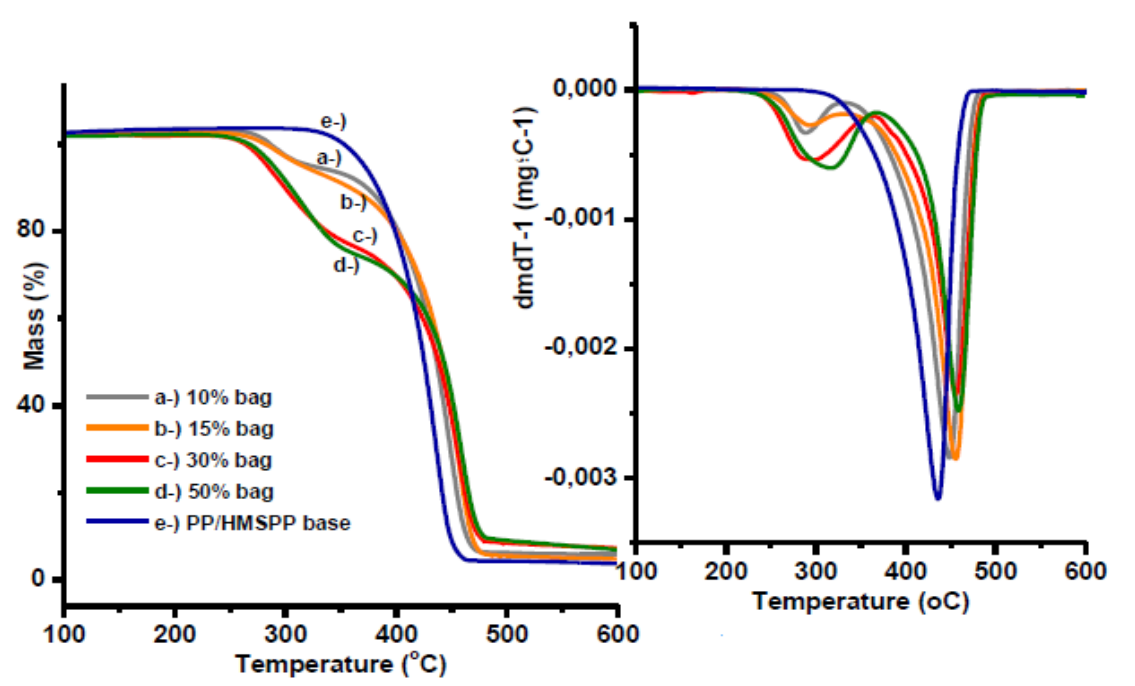

Figure 1(a): TG for sugarcane bagasse foams Figure 1(b): DTG for sugarcane bagasse foams

It occurs a first mass loss within room temperature and $250{ }^{\circ} \mathrm{C}$, attributed to absorbed water or water bound to vegetal fiber, corresponding to approximately $4 \%$ mass loss. Within 250 and 460 ${ }^{\circ} \mathrm{C}$ it occurs a mass loss attributed to thermal degradation of organic compounds, especially cellulose, hemicelluloses and lignin $[13,14,15]$. Hemicellulose is the component with lower thermal stability, within 200 to $260{ }^{\circ} \mathrm{C}$ degradation temperature followed by cellulose, within 240 to $350^{\circ} \mathrm{C}$. Lignin presents a higher thermal stability and it is thermally degraded within 280 to 500 ${ }^{\circ} \mathrm{C}$. So, medium degradation temperature for sugarcane bagasse foams attained $460{ }^{\circ} \mathrm{C}$, superior to that one found for PP/HMSPP polymeric base: $420^{\circ} \mathrm{C}$.

\section{PHB foams:}

TG and DTG curves for PHB foams presented in Table 1 are shown in Figures 2 (a) and 2(b), respectively: 


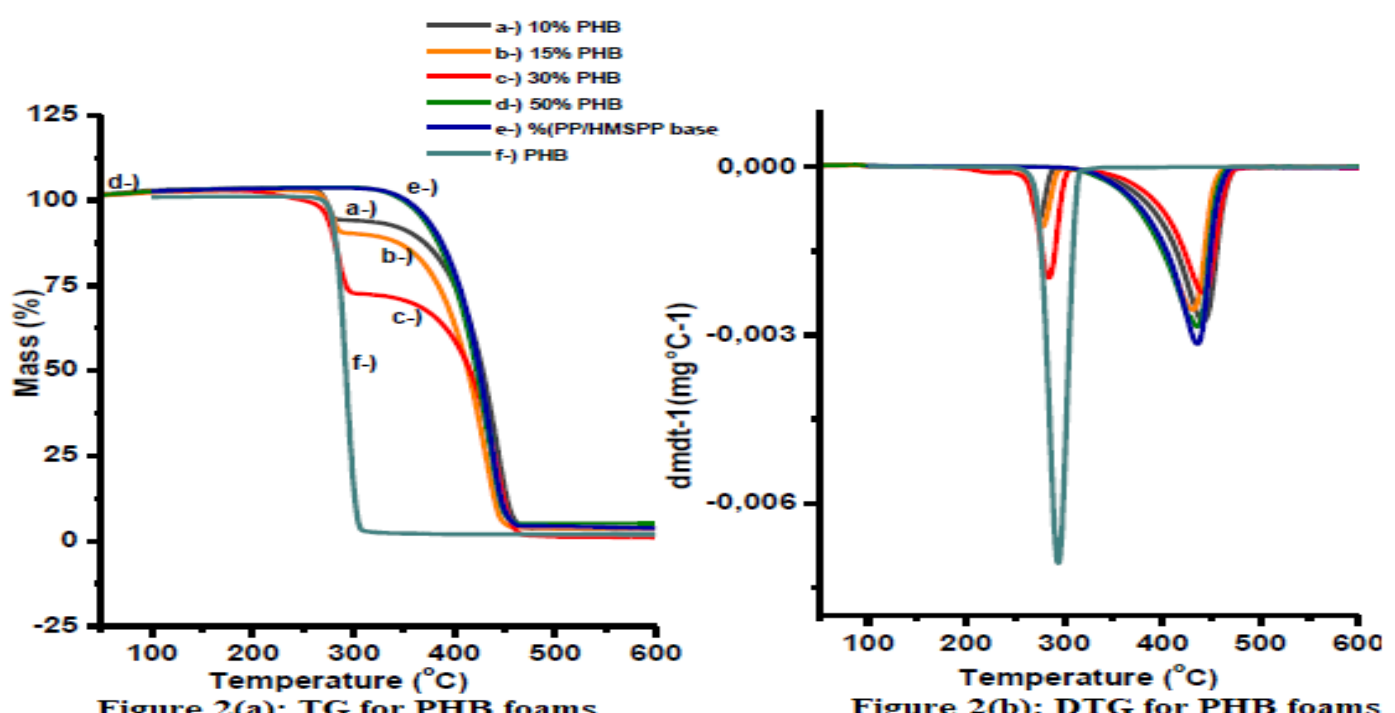

PHB appears to have two main overall degradation steps while compounds degradation is complex constituting of several processes. Whilst these results are suggestive that the addition of PHB to PP/HMSPP basis promotes PHB degradation, it does not, however, give a quantitative assessment of the overall stability of blends. As shown in Figure 2 (a), degradation of pure PHB is complete at $300{ }^{\circ} \mathrm{C}$. The lower weight loss is an indication that the blends are thermally more stable than PHB over a wider temperature range $[16,17,18]$. Thermal degradation of pure PHB and PP/HMSPP basis occurs through one step, characterised by a single peak on Figure 2(b).

\section{Tensile force and elongation at break:}

\section{Sugarcane bagasse foams:}

Mechanicals assessments for sugarcane bagasse foams are shown in Figure 3:

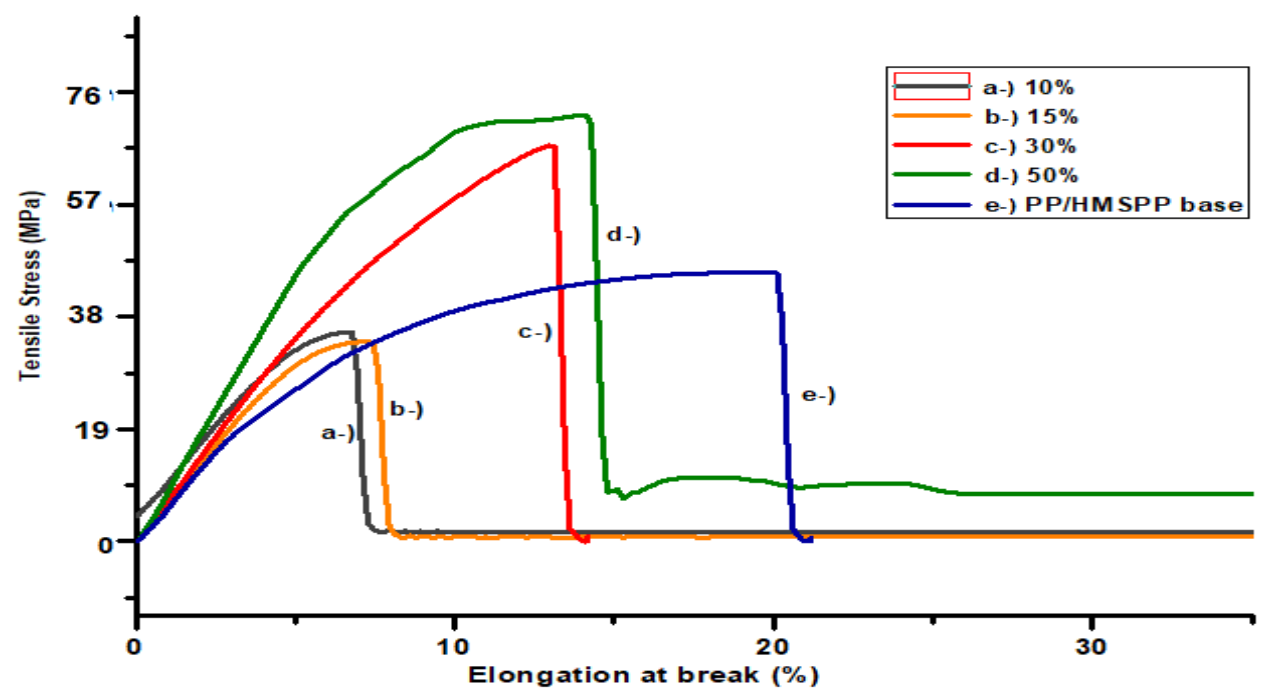

Figure 3. Mechanical behavior of sugarcane bagasse foamed compositions. 
All sugarcane bagasse foamed compositions exhibited tensile stress values higher than that one presented by PP/HMSPP polymeric base, proportionally on increasing bagasse contents. So, it was ratified that sugarcane bagasse plays the role of reinforcing agent. Nevertheless, elongation at break for all sugarcane bagasse foamed compositions showed lower values when compared to PP/HMSPP base.

\section{PHB foams}

Mechanicals assessments for PHB foams are shown in Figure 4:

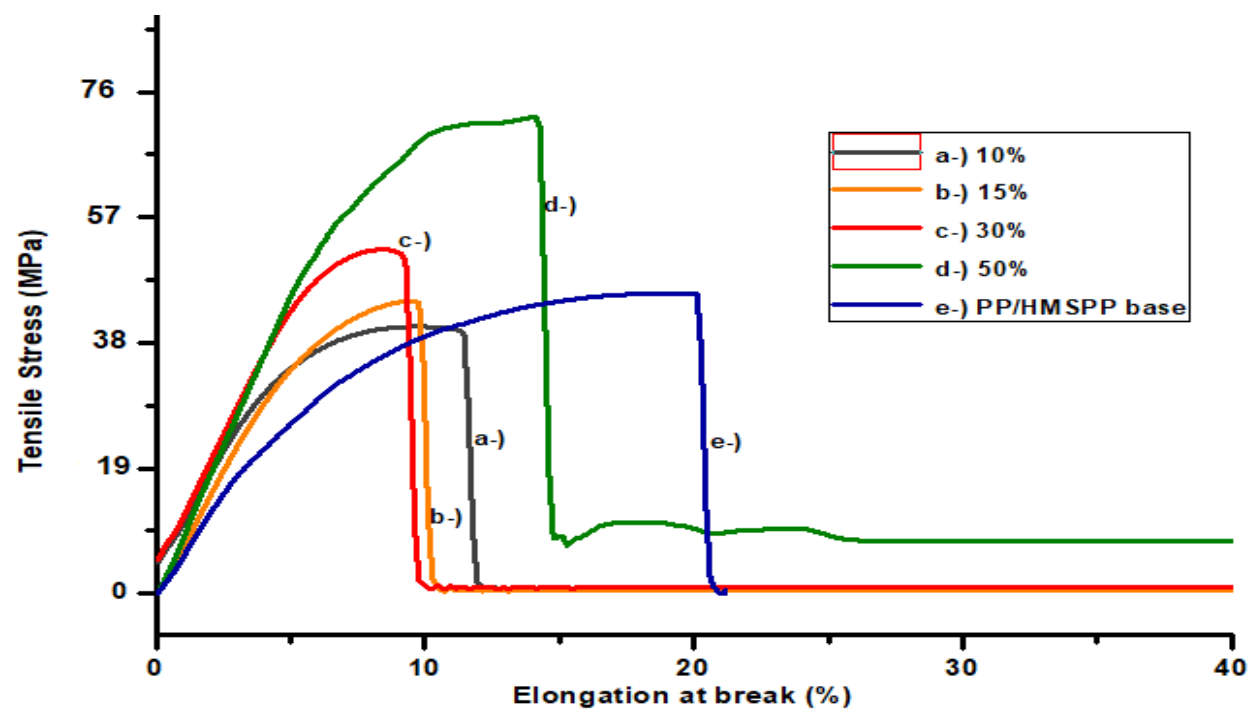

Figure 4. Mechanical behavior of PHB foamed compositions.

$30 \%$ and $50 \%$ PHB foamed compositions showed tensile higher than that one found for PP/HMSPP base; elongation at break for all foamed PHB compositions presented values lower than that one found for PP/HMSPP base.

\section{Soil burial test:}

\section{Prior to gamma-radiation treatment to induce biodegradability:}

In Table 2 are shown mass loss for foamed compounds after 12 month - period of soil buried:

Table 2. Mass variation index for foamed compounds after 12 month-period soil buried

\begin{tabular}{c|cc}
\hline & $\begin{array}{c}\text { Sugarcane bagasse } \\
\text { foams }\end{array}$ & PHB foams \\
\hline$\%$ & & \\
$10 \%$ & 21.30 & 0.10 \\
$15 \%$ & 22.50 & 0.12 \\
$30 \%$ & 29.20 & 0.16 \\
$50 \%$ & 32.40 & 0.19 \\
\hline
\end{tabular}


Results shown in Table 2 indicate that just foamed sugarcane bagasse foams were susceptible to soil burial test after 12 months. PHB foamed compounds showed negligible results for soil burial test.

\section{Gamma-radiation treatment:}

All foamed samples were subjected to gamma radiation within 50, 100, 150, 200 and 500 kGy. At first, there were performed mechanicals tests, prior to soil burial tests, according presented in Figures 5 and 6, respectively.
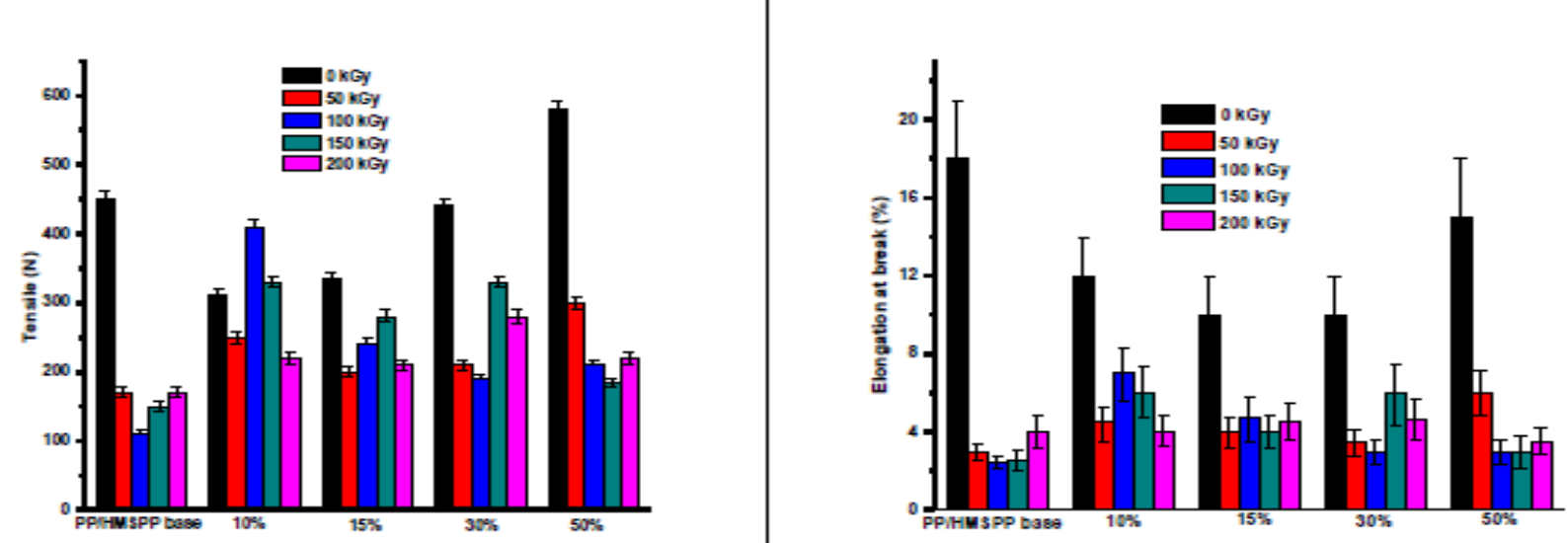

Figure 5.Tensile and Elongation at break for sugarcane bagasse foams after gamma- radiation at: 50, 100, 150 and $200 \mathrm{kGy}$.

Results presented in Figure 5 indicated that PP/HMSPP base showed susceptible to gamma radiation, with a visible reduction in tensile and elongation at break, when compared to sugarcane bagasse foams. It should be emphacized that 100 to $600 \mathrm{~N}$ range for Tensile Load corresponds to 12 to $75 \mathrm{MPa}$ for Tensile Stress.
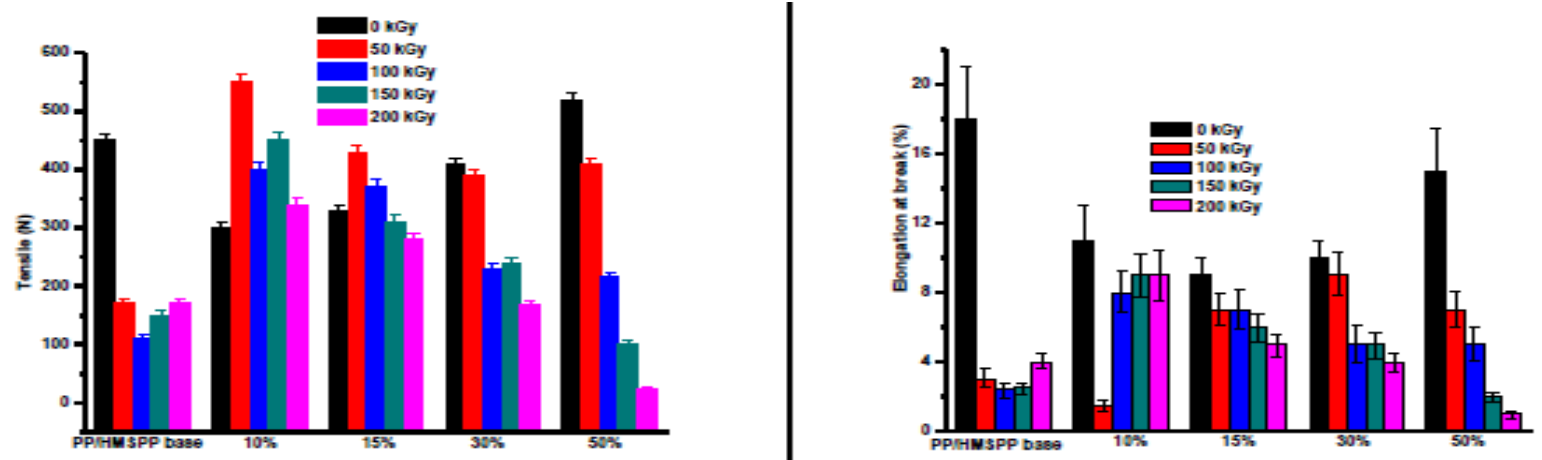

Figure 6. Tensile and Elongation at break for PHB foams after gamma-radiation at: 50, 100, 150 and $200 \mathrm{kGy}$. 
Results presented in Figure 6 indicated that PP/HMSPP base showed susceptible to gamma radiation, with a visible reduction in tensile and elongation at break, when compared to PHB foams. It should be emphacized that 100 to $600 \mathrm{~N}$ range for Tensile Load corresponds to 12 to 75 MPa for Tensile Stress.

Soil burial tests in irradiated sugarcane bagasse and, PHB foams presented mass loss according depicted in Table 3:

Table 3. Mass variation index for foamed compounds gamma irradiated at $200 \mathrm{kGy}$ and 500 kGy, after 12 month-period soil buried

\begin{tabular}{|l|c|c|c|c|}
\hline$\%$ & $\begin{array}{c}\text { Sugarcane bagasse foams } \\
200 \mathrm{kGy}\end{array}$ & $500 \mathrm{kGy}$ & $\begin{array}{c}\text { PHB foams } \\
200 \mathrm{kGy}\end{array}$ & $500 \mathrm{kGy}$ \\
\hline 10 & & & & \\
\hline 15 & $* * *$ & $* * *$ & 4.80 & 10.30 \\
\hline 30 & $* * *$ & $* * *$ & 5.20 & 11.60 \\
\hline 50 & $* * *$ & $* * *$ & 6.90 & 15.90 \\
\hline & $* * *$ & $* * *$ & 7.40 & 20.10 \\
\hline
\end{tabular}

Sugarcane bagasse irradiated foams presented final values higher than initial ones due to surface erosion caused by gamma radiation; even impossible to quantify mass loss due to water uptake, the biodegradability will be imparted in these samples by micro- organisms action. Non irradiated PHB foams presented negligible values for mass loss, according to Table 2 ; even within 200 and 500 kGy doses PHB foams showed a slight biodegradability development. Nevertheless, PHB foams showed a higher mass loss when compared with PP/HMSPP polymeric base that showed a negligible mass loss equal to $1.9 \%$, even at $500 \mathrm{kGy}$ and after one year of soil buried.

\section{CONCLUSIONS}

It is possible the incorporation of sugarcane bagasse and PHB in structural foams PP/HMSPP base and further turn them into partially biodegradable ones. Thermogravimetric tests presented expected results for sugarcane bagasse and PHB PP/HMSPP base foams. Mechanical essays proved that either natural polymer (sugarcane bagasse) as synthetic PHB one acted as reinforcing agent even after gamma-radiation imparted on them. PP/HMSPP polymeric base presented a expected negligible result of mass loss after one year of soil buried even after gamma-radiated at $500 \mathrm{kGy}$, proving non-biodegradable characteristic of fossil polymers. Non-irradiated sugarcane bagasse foams presented better biodegradability efficiency when compared to PHB foams, after one year of soil burial, even with soil burial measurements prejudiced due to water-uptake fostered in damaged surfaces; nevertheless, hydrolysis favored water inlet through damaged surfaces and consequently biodegradability by microorganism action. 
$4^{\text {th }}$ Brazilian Conference on Composite Materials. Rio de Janeiro, July $22^{\text {nd }}-25^{\text {th }}, 2018$

\section{ACKNOWLEDGEMENTS}

The authors thank to Braskem, Nature Works, PHB Industrial and Celanese by raw- materials supply, IPEN/CNEN-SP and CNEN for their financial support through 0134.000411/2013-20 post doctorate process.

\section{REFERENCES}

[1] C. Longo, M.Savaris, M. Zani, R. M. Brandalise, A. M. C. Gris, 'Degradation Study of Polypropylene (PP) and Bi-oriented Polypropylene (BOPP)'. Environment Materials Research 14 (4), (2011) 442-448.

[2] J. Arutchelvi; M. Sudhakar; A. Arkatkar; M. Doble; S. Bhaduriandp; V.Uppara, Indian Journal of Biotechnology, 7, (2008) $9-22$.

[3] Chandra, R; Rustgi, R., Polym. Degrad. Stab. 56, (1997) 185.

[4] Y.Tokiwa, B. P. Calabia, C. U. Ugwu and S. Aiba, Int. J. Mol. Sci,10, (2009) 3722-3742.

[5] E. Chiellini; P. Cinelli; R. Solaro; M. Laus, 'Thermomechanical Behavior of Poly(vinyl alcohol) and Sugarcane Bagasse Composites`, Journal of Applied Polymer Science, 92, (2004) 426-432,.

[6] Lugão et al, `Process for preparing high melt strength polypropylene and crosslinked prepared therewith`, U. S. Patent 20040171712, (2004).

[7] Ademar B. Lugão; Elizabeth C. L.Cardoso, Luis Filipe C. P. Lima, Beatriz Hustzler, Shinichi Tokumoto, 'Characterization study of gamma-irradiated, high melt strength polypropylene', Nuclear Instruments and Methods in Physics Research, Section B: Beam interactions with materials and atoms, Ionizing Radiation and Polymers, 208, (2003) 252-255.

[8] Cardoso, E.C.L., `Desenvolvimento de espumas a partir de misturas poliméricas de PP linear e HMSPP`, Thesis (MSC) - IPEN/CNEN, SP, (2010).

] ASTM E 1641 - 07, Standard Test Method for Decomposition Kinetics by Thermogravimetry.

[10] Natalia Naime, 'Embalagens ativas de fonte renovável ', Dissertação, IPEN - Instituto de Pesquisas Energéticas e Nucleares, São Paulo, (2010).

11 ] N. Lardjane et al, 'Soil burial degradation of new bio-based additives`, Journal of Vinyl and Additive Technology 7 (2), (2011) 98-104.

[12] N. Vogelsager Jr et al, 'Acompanhamento da Biodegradação em Solo por Propriedades Térmicas e Morfológicas`, Revista Matéria, 9, n.4, (2004) 370 - 377.

[13] Seung-Hwan Lee, Siqun Wang, 'Biodegradable polymers/bamboo fiber biocomposite with bio-based coupling agent', Composites: Part A, 37, (2006) 80 - 91.

[14] E. Chiellini, P. Cinelli, R. Solaro, M. Laus, 'Thermomechanical Behavior of Poly(vinyl alcohol) and Sugar Cane Bagasse Composites`, Journal of Applied Polymer Science, 92, (2004) 426-432.

[15] Amir Hooman Hemmasi, Ahmad Samariha, Asghar Tabei, Mohammad Nemati and Alireza Jkhakifirooz, 'Study of Morphological and Chemical Composition of Fibers from Iranian Sugarcane Bagasse ', American-Eurasian J. Agric. \& Environ. Sci., 11 (4): (2011) 478-481.

[16] Haffar, A.M.E.A., 'Development of a biodegradable material based on Poly(3hydroxybutyrate) PHB ', Ph.D. Thesis, Martin-Luther University, Wittenberg, Germany, (2002).

[17] Mochizuki, M.; Hirami, M., 'Structural effects on biodegradation of aliphatic polyesters`, Polym. Adv. Technol. 8, (1997), 203.

[18] E. Bugnicourt, P. Cinelli; A. Lazzeri; V. Alvarez, 'Review of synthesis, characteristics, processing and potential application in packaging`, Express Polymers Letters, 18, nr. 11, (2014) $791-801$. 